\title{
Avaliação de matéria orgânica, densidade e porosidade do latossolo vermelho em contato com lixiviado de resíduos sólidos urbanos
}

\author{
Evaluation of organic matter, density and porosity \\ of Oxisol in contact with leachate from urban solid waste
}

Vanessa Lasaro Mangieri'* ${ }^{(0)}$, João Tavares Filho ${ }^{2}$

\section{RESUMO}

O objetivo do trabalho é avaliar a densidade, a porosidade e a matéria orgânica do solo decorrentes da interação solo-lixiviado em um latossolo vermelho, em duas profundidades: 0,2 e 1,5 m. As amostras de solo foram coletadas indeformadas, e o lixiviado em aterro foi controlado. Utilizaramse colunas de difusão, sem fluxo, onde o solo ficou submerso no lixiviado durante 90 dias. A matéria orgânica do solo (MOS) foi obtida por meio de determinação gravimétrica (IAPAR). Densidade, micro e macroporosidade foram obtidas de acordo com o ensaio de mesa de tensão (EMBRAPA). Foram realizadas análises de regressão para estudar os efeitos dos fatores e suas interações para o parâmetro da matéria orgânica. As principais conclusões foram: as maiores alterações nas propriedades físicas do solo ocorrem nos primeiros dias de contato; a densidade do solo a 0,2 m reduziu 5,9\%, enquanto a 1,5 m aumentou 5,61\%; a macroporosidade não se alterou a 0,2 m, mas foi reduzida em 11\%, para 1,5 m; a microporosidade para as duas profundidades estudadas aumentou, respectivamente, em 4,25 e 21,14\%. A MOS teve baixa correlação com a demanda bioquímica de oxigênio $\left(\mathrm{DBO}_{5}\right)$ do lixiviado e uma correlação significativa com a sua demanda química de oxigênio (DQO); e seu aumento foi significativo no período de contato.

Palavras-chave: densidade e porosidade do solo; resíduos sólidos urbanos; lixiviado.

\begin{abstract}
The objective of this research is to evaluate soil density, porosity, and also the organic matter due to soil-leachate interaction in Oxisol, at two depths: 0.2 and $1.5 \mathrm{~m}$. Soil samples were collected undisturbed and the leachate in a landfill. Diffusion columns, without any flow, were used, where the soil was submerged in the leachate for 90 days. The organic matter was obtained by gravimetric determination (IAPAR). Density, micro and macro porosity were obtained according to the stress table test (EMBRAPA). Regression analysis was performed to study the factors effects and their interactions for the organic matter parameter. The main conclusions were: major changes in physical soil properties occur in the first days of contact; soil bulk density at $0.2 \mathrm{~m}$ decreased by $5.9 \%$, while at $1.5 \mathrm{~m}$ it increased by 5.61\%; macroporosity did not changed to $0.2 \mathrm{~m}$, but decreased by $11 \%$ for $1.5 \mathrm{~m}$; microporosity for both depths studied increased, respectively, by 4.25 and $21,14 \%$. The soil organic matter had a low correlation with the leachate $\mathrm{BOD}_{5}$ and a significant correlation with its COD; the increase of the soil organic matter was significant at the time of the contact.
\end{abstract}

Keywords: soil density and porosity; municipal solid waste; leachate.

\section{INTRODUÇÃO}

A disposição de resíduos sólidos urbanos no solo gera um líquido denominado de lixiviado, o qual demanda recursos financeiros e espaços para o seu tratamento. O uso agrícola é uma alternativa de disposição do lixiviado, pois o uso desse líquido pode ser promissor na agricultura.

Segundo Barros et al. (2005), as formas de disposição e depuração de esgotos e de águas residuárias de suínos sobre o solo têm sido apontadas como alternativa barata e viável. Essa forma de disposição tem por objetivo a redução dos custos de tratamento, o reaproveitamento dos nutrientes e o melhoramento das condições físicas e químicas do solo; no entanto, deve ser feita de forma cuidadosa, para que não venha contribuir com a contaminação de águas subterrâneas, superficiais e de plantas e não tragam efeitos negativos sobre os atributos físicos e químicos do solo (MATOS et al., 1997). 
O uso incorreto das águas residuárias de suínos pode trazer efeitos deletérios ao solo, como o entupimento dos macroporos, causando o selamento superficial que dificulta a infiltração de água e a troca de gases entre a atmosfera e o solo; além disso, também oferece o risco de salinização do solo, poluição de solo e plantas com metais pesados e contaminação do homem e animais por agentes patogênicos provenientes dos dejetos (MATOS et al., 1997).

Em relação aos atributos físicos, a aplicação de lodo de esgoto no solo promove aumento na porosidade total e macroporosidade (ORTEGA; NOGALES; DELGADO, 1981; PAGLIAI et al., 1981; MATHAN, 1994), diminuição na densidade do solo (AGGELIDES; LONDRA, 2000) e maior retenção de água (KUMAR; MALLIK; DAHIYA, 1985; AGGELIDES; LONDRA, 2000; DEBOSZ et al., 2002). Quanto à retenção de água no solo, a matéria orgânica tem efeitos indiretos, atuando tanto no aumento da agregação e da porosidade quanto na diminuição da densidade do solo (METZGER; YARON, 1987).

Regiões de clima tropical e subtropical apresentam predominância de solos muito intemperizados, com baixos conteúdos de matéria orgânica e nutrientes disponíveis. Nessas situações, o uso agrícola de resíduos orgânicos, como lodo de esgoto, pode ser vantajoso (SIMONETE et al., 2003). O uso agrícola desses resíduos tem sido recomendado por proporcionar benefícios agronômicos, como elevação do pH do solo (SILVA et al., 2001), redução da acidez potencial (BERTON; CAMARGO; VALADARES, 1989) e aumento na disponibilidade de macronutrientes (DA ROS et al., 1993; BERTON et al., 1997), representando um benefício à sociedade pela disposição final menos impactante ao meio ambiente.

Foram encontrados, na literatura, trabalhos referentes à contaminação do solo com metais. Estes apresentam a adsorção de alguns metais pelo solo por meio de programas computacionais que fornecem curvas de adsorção do solo para os elementos estudados. Gabas (2005) realizou atividades experimentais para avaliar a forma de retenção dos metais cádmio e chumbo em solos latossólicos compactados. Leite (2001), em seu trabalho, utilizou amostras de um solo residual das Formações Botucatu e Serra Geral. Esses solos foram misturados entre si com diferentes porcentagens e ensaiados. Nos ensaios de difusão, foram feitos estudos de migração dos íons cátion monovalente de potássio $(\mathrm{K}+)$, cátion bivalente de cádmio $(\mathrm{Cd} 2+)$, ânion cloreto $(\mathrm{Cl}-) \mathrm{e}$ ânion fluoreto (F-) em amostras compactadas e saturadas. No trabalho de Leite (2001), as discussões giram em torno dos ajustes computacionais obtidos por meio de experimentos nas amostras e da obtenção do coeficiente de difusão $\left(\mathrm{D}^{\star}\right)$. Ritter e Campos (2006) avaliaram resultados de ensaio de medida da interação solo-contaminante (sorção) e do transporte de diversas espécies químicas (difusão molecular) em diferentes amostras do solo do aterro metropolitano de Gramacho (RJ).

Atualmente, pesquisadores utilizam a disposição de lodo de esgoto e águas residuárias de animais no solo como alternativa de disposição desses resíduos e também como forma de proporcionar benefícios ao solo, acrescentando matéria orgânica, elevação de $\mathrm{pH}$ e aumento da disponibilidade de nutrientes. Assim como as águas residuárias de suínos e lodos de esgoto, a disposição de lixiviado proveniente de resíduos sólidos urbanos no uso agrícola deve ser avaliada como forma de disposição final desse produto e como essa disposição contribui para as propriedades do solo, já que o lixiviado é constituído de substâncias orgânicas e inorgânicas.

Trabalhos que envolvem avaliação do solo após contato com o lixiviado são escassos. Portanto, é fundamental o conhecimento da interação solo-lixiviado para avaliar sua qualidade e qual a contribuição dessa interação.

O objetivo do trabalho foi avaliar impactos nas propriedades físicas e na matéria orgânica decorrentes da interação do solo com lixiviado proveniente de resíduos sólidos urbanos.

\section{METODOLOGIA}

O solo utilizado foi um Latossolo Vermelho argiloso, do qual as amostras foram coletadas nas camadas de 0 a 20 e de 150 a $170 \mathrm{~cm}$ de profundidade. Esse solo encontra-se em uma área nativa sem antecedentes de usos agrícola ou pecuário. Para a coleta do solo indeformado, nas profundidades citadas, blocos de $30 \times 30 \times 30 \mathrm{~cm}$ foram moldados e devidamente envoltos com tecido e parafina para manutenção das propriedades naturais. As características químicas e físicas das amostras utilizadas, antes do experimento, eram para as duas amostras respectivamente: $\mathrm{pH}$ em cloreto de cálcio $\left(\mathrm{CaCL}_{2}\right), 4,3$ e 4,4; matérias orgânicas do solo (MOS) de 54,6 e 39,9 g. $\mathrm{dm}^{-3}$; teores de argila de 726 e 757 g.kg-1 densidades do solo saturado de 0,916 e 0,909 g.mL ${ }^{-1}$; macroporosidade de 0,315 e $0,335 \mathrm{~m}^{3} \cdot \mathrm{m}^{-3}$; e microporosidade de 0,327 e $0,298 \mathrm{~m}^{3} \cdot \mathrm{m}^{-3}$. As características $\mathrm{pH}$ e MOS foram obtidas pela estimativa das atividades dos íons hidrônios $\left(\mathrm{H}^{+}\right)$na suspensão do solo, utilizando-se a solução $\mathrm{CaCl}_{2} 0,01 \mathrm{M}$, e por meio do método de determinação gravimétrica, que se baseia no princípio da perda de massa da matéria orgânica, presente no solo, quando submetido à incineração. O método foi desenvolvido pelo Instituto Agronômico do Paraná (IAPAR). As propriedades de densidade, macro e microporosidade foram obtidas de acordo com o ensaio da mesa de tensão proposto pela Embrapa (1997).

O lixiviado utilizado foi coletado no local de deposição de resíduos sólidos do município de Londrina, classificado como aterro controlado e armazenado e mantido em refrigeração a $4^{\circ} \mathrm{C}$ em cinco galões de 20 litros até a montagem do experimento. As características iniciais do lixiviado antes do experimento foram: $\mathrm{pH}$ de 8,1; demanda química de oxigênio (DQO) de $1.556 \mathrm{mgO}_{2} \cdot \mathrm{L}^{-1}$ e demanda bioquímica de oxigênio $\left(\mathrm{DBO}_{5}\right)$ de $300 \mathrm{mgO}_{2} \cdot \mathrm{L}^{-1}$, caracterizado pelas técnicas analíticas do Standard Methods for the examination of water \& wastewater (APHA; AWWA; WEF, 2005). 
Para obtenção da MOS, utilizaram-se células de difusão. Foram moldados corpos de prova de solo indeformado, das duas profundidades, de modo que representem as diferentes condições encontradas no campo. A quantidade de células de difusão para as profundidades de 0,2 e 1,5 m foi montada de acordo com o número de dias planejados para a retirada das amostras. A célula de difusão utilizada foi feita de tubo em policloreto de vinila (PVC) branco, com $10 \mathrm{~cm}$ de diâmetro e $12 \mathrm{~cm}$ de altura, biselado em sua parte inferior de forma que facilite a cravação no solo durante a moldagem do corpo de prova. As dimensões da célula de difusão foram determinadas em função do volume de lixiviado necessário para as análises químicas previstas para o líquido, ou seja $6,3 \mathrm{~cm}$. Para a altura do solo, optou-se por adotar as medidas da coluna de Barone (1989) - 4,5 cm de solo.

Um tampão de PVC, do mesmo diâmetro do tubo, foi colocado na parte inferior para conter o lixiviado na célula. A Figura 1 mostra o esquema da coluna de difusão.

Todos os corpos de prova foram previamente identificados como solos a 0,2 ou 1,5 m antes da saturação. A saturação dos corpos de prova foi feita pelo orifício da parte inferior do CAP. O perímetro em torno da extremidade deste foi estancado com o uso de borracha de silicone, impedindo a ocorrência de vazamentos de lixiviado pelo contato entre CAP e tubo. Após a saturação, o orifício foi fechado com borracha sintética. Foram colocados $500 \mathrm{~mL}$ de lixiviado nas células, volume necessário para as análises programadas e para o fechamento destes com filme plástico para proteção.

As amostras, tanto do solo como do lixiviado, foram retiradas diariamente até o décimo dia de contato, uma vez por semana da terceira até a sexta semana e a partir da sétima semana a cada 15 dias até completar o período de 90 dias. Primeiramente, foi extraído o líquido sobrenadante, tanto do solo a $0,2 \mathrm{~m}$ como do a $1,5 \mathrm{~m}$, com auxílio de pipeta e tomando-se o cuidado necessário para não perturbar o solo.
Após a extração, o líquido foi armazenado em recipientes plásticos previamente identificados.

Após a retirada do líquido, as amostras do solo permaneceram dentro do CAP para drenagem por três dias, para não ocorrer desestruturação. O solo continuava secando ao ar livre após retirado das células por, no mínimo, sete dias. Depois de completada a secagem ao ar livre, o solo passou pela moagem e pelo peneiramento, em malha de abertura de $12 \mathrm{~mm}$, foi armazenado em sacos plásticos com identificação das amostras e do dia de extração da célula e foi submetido às análises químicas e físicas, conforme descrito acima. As análises foram feitas com amostras simples, sem repetição das colunas, em função da degradação do líquido.

Para a análise estatística dos dados, usou-se regressão simples, com intervalo de confiança de $70 \%$ para a matéria orgânica e de $95 \%$ para os dias de contato, utilizando o programa Statistica versão 6.0.

Para as determinações de densidade, macro e microporosidade do solo, foram utilizados os solos e o lixiviado coletados para as células de difusão. Foram moldadas seis amostras de solo de cada profundidade, sendo três saturadas com água e três com lixiviado. Elas foram moldadas em anéis de PVC, saturadas com água e lixiviado e submetidas ao ensaio de mesa de tensão, conforme metodologia proposta pela Embrapa (1997).

\section{RESULTADOS E DISCUSSÃO}

As propriedades físicas e a MOS foram avaliadas em função da interação entre o lixiviado e o solo. Verificou-se que esses atributos variaram quando em contato com o lixiviado.

Nesse experimento, quando o solo ficou em contato com o lixiviado pelo tempo determinado de 90 dias, a matéria orgânica do lixiviado $\left(\mathrm{DBO}_{5}\right)$ reduziu, enquanto a MOS aumentou (Figura 2).

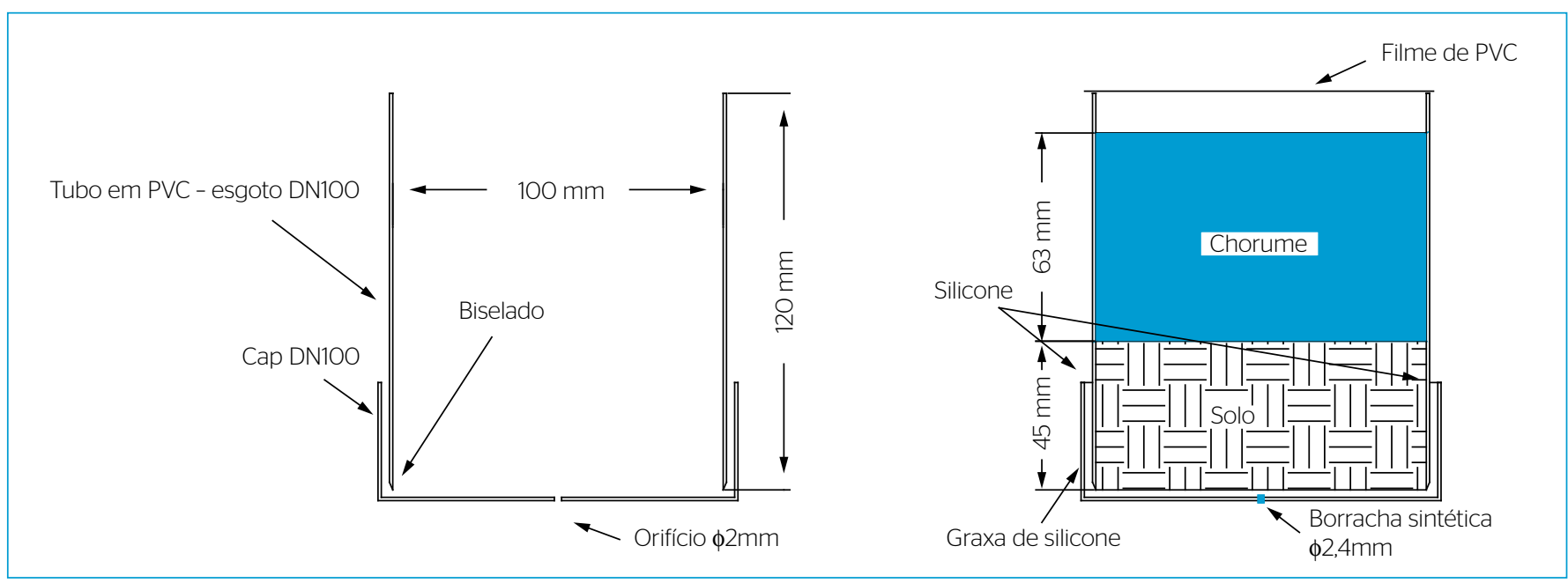

Figura 1 - Esquema de montagem do ensaio de difusão. 
$\mathrm{Na}$ Figura 2, a relação entre a MOS a 0,2 $\mathrm{m}$ de profundidade e a $\mathrm{DBO}_{5}$ que ficou em contato com esse solo é significativa a 30\%, com valor $\mathrm{p}$ de 0,3077 . Verifica-se que a matéria orgânica presente no lixiviado é transferida para o solo em função da correlação negativa, $r=-0,3218$, mesmo esta sendo baixa. Essa diminuta correlação pode ser explicada em função da quantidade inicial de matéria orgânica já presente no solo da amostra a $0,2 \mathrm{~m}$, de $56,6 \mathrm{~g} \cdot \mathrm{dm}^{-3}$, provavelmente por ser uma amostra de solo de superfície.

$\mathrm{Na}$ amostra de profundidade a 1,5 m (Figura 3), observa-se o mesmo comportamento da outra amostra, porém a correlação

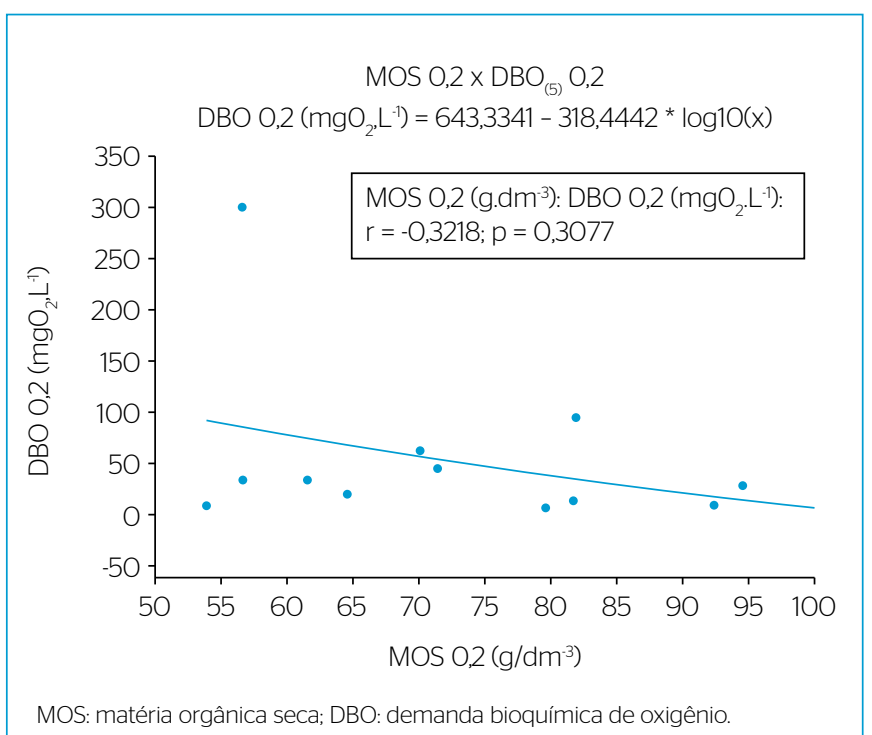

Figura 2 - Relação entre a matéria orgânica do lixiviado $\left(\mathrm{DBO}_{5}\right)$ e a seca a $0,2 \mathrm{~m}$ no ensaio de difusão.

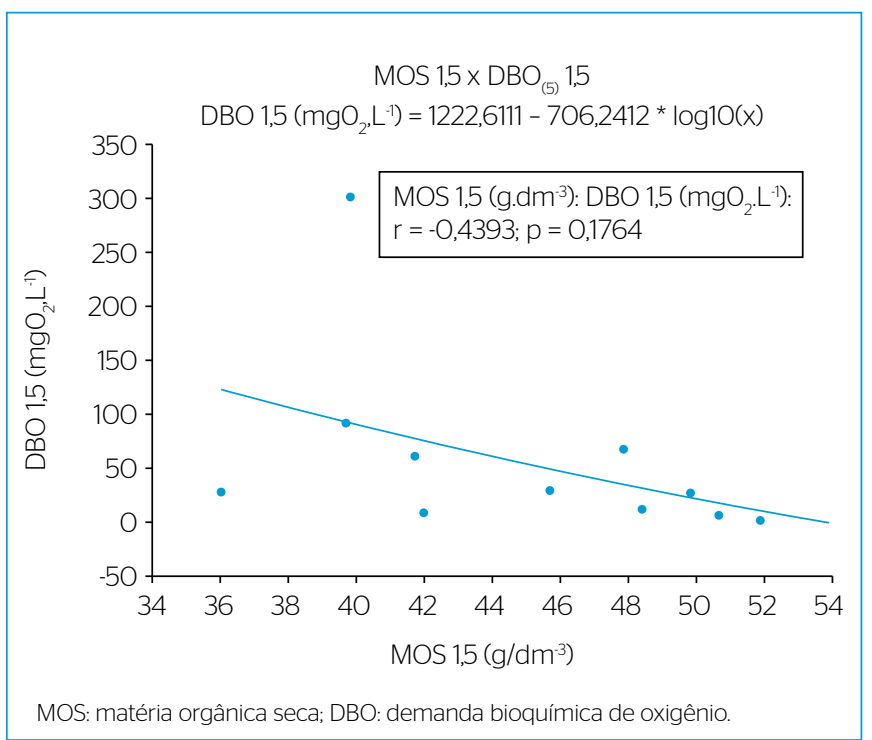

Figura 3 - Relação entre a matéria orgânica do lixiviado $\left(\mathrm{DBO}_{5}\right)$ e a seca a 1,5 m no ensaio de difusão. negativa entre os parâmetros é maior $-\mathrm{r}=-0,4393-$, também significativa a $30 \%$ e com transferência de matéria orgânica para o solo. Esse processo pode ser explicado por ter a amostra do solo a $1,5 \mathrm{~m}$ quantidade inicial menor de matéria orgânica que o a 0,2 m - 39,9 g.dm ${ }^{-3}$, absorvendo, assim, maior quantidade de matéria orgânica do que a outra amostra. Nos dois casos, há tendência logarítmica entre esses dois parâmetros, tendendo a se estabilizar com o tempo.

O lixiviado também apresenta, em sua composição, matéria orgânica dificilmente degradável, medida pela DQO (Figura 4).

Nos resultados obtidos para o solo a $0,2 \mathrm{~m}$ de profundidade, verificou-se que os parâmetros DQO e MOS tem uma correlação negativa de $-0,1660$ e não significativa a $30 \%$, ou seja, os parâmetros não se correlacionam entre si. Porém, a matéria orgânica dificilmente degradável do lixiviado também está passando para o solo a 0,2 m (Figura 4), apesar da baixa correlação. Observa-se o mesmo comportamento desse parâmetro com a $\mathrm{DBO}_{5}$, quando em contato com o solo de $0,2 \mathrm{~m}$ de profundidade.

Com relação à amostra do solo a 1,5 m (Figura 5), nota-se o mesmo comportamento do solo a $0,2 \mathrm{~m}$, pois há correlação negativa de $-0,5150 \mathrm{e}$ significativa a $30 \%$, no qual a matéria orgânica do lixiviado, em DQO, é transferida para o solo da amostra de 1,5 $\mathrm{m}$ de profundidade. Uma hipótese para esse desempenho seria uma baixa ou ausência de atividade microbiana nessa profundidade, podendo o solo absorver mais matéria orgânica.

Ao verificarmos a relação da matéria orgânica em função do tempo de contato com o lixiviado, nota-se que há uma tendência logarítmica e, ao passar dos dias, essa relação é significativa a $5 \%$ para os solos a 0,2 e $1,5 \mathrm{~m}-\mathrm{p}=0,0366$ e 0,011 , respectivamente - , havendo uma

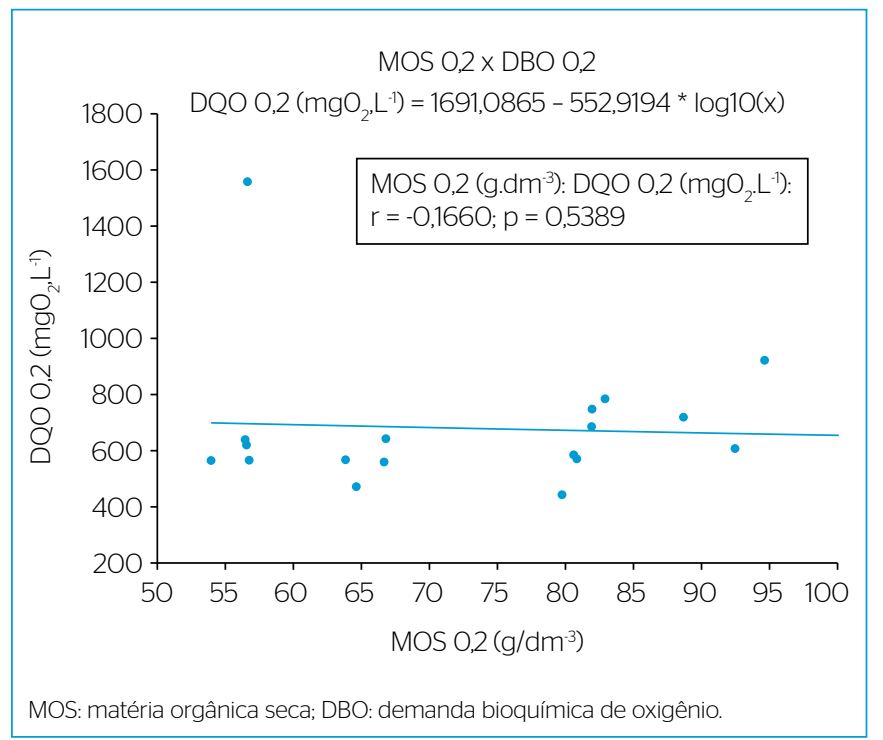

Figura 4 - Relação entre a matéria orgânica do lixiviado (DQO) e a seca a $0,2 \mathrm{~m}$ no ensaio de difusão. 
correlação positiva de 0,4479 entre os parâmetros para o solo a 0,2 m e de 0,6488 para o a $1,5 \mathrm{~m}$ (Figuras 6 e 7). As correlações obtidas atestam que é no solo da amostra a 1,5 m que há maior absorção de matéria orgânica. Verifica-se também que, nos primeiros dias de contato, há um aumento maior da matéria orgânica do solo, tanto para o a $0,2 \mathrm{~m}$ quanto para o a $1,5 \mathrm{~m}$, indicando que é na fase inicial do contato que há maior incorporação dessa matéria orgânica.

Além da alteração química, os solos podem apresentar alterações físicas (MCSWEENEY; JANSEN, 1984). Observa-se, pela Tabela 1, que, comparando-se as propriedades do solo saturado com água e lixiviado,

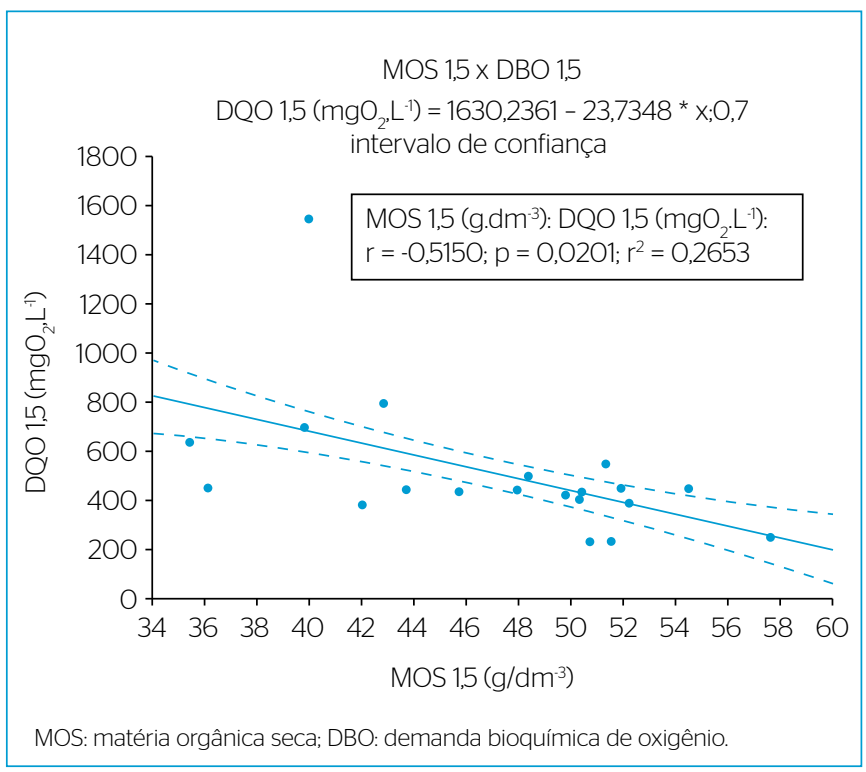

Figura 5 - Relação entre a matéria orgânica do lixiviado (DQO) e a seca a $1,5 \mathrm{~m}$ no ensaio de difusão.

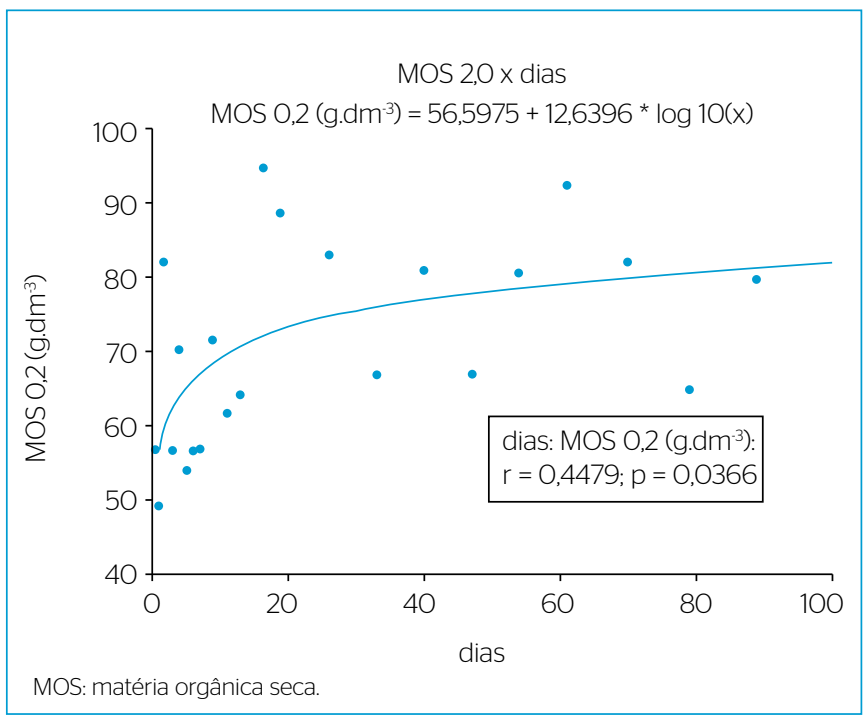

Figura 6 - Relação entre a matéria orgânica seca a 0,2 m e o tempo de contato no ensaio de difusão. este alterou as densidades nas duas profundidades e a porosidade do solo (macro e microporosidade).

Contrapondo-se o resultado da média simples de três amostras de solo tanto em contato com a água quanto com o lixiviado, verificaram-se alterações na densidade (saturada) e nas macro e microporosidade do solo (Tabela 1). A densidade do solo saturado, na profundidade de 0 a $0,2 \mathrm{~m}$, reduziu em $5,90 \%$, enquanto, na profundidade de $1,5 \mathrm{~m}$, aumentou 5,61\%. A macroporosidade do solo a $0,2 \mathrm{~m}$ se elevou discretamente (1,58\%), e a 1,5 m reduziu (11,00\%). Já a microporosidade das duas amostras aumentou, 4,25 e 21,14\%, respectivamente, nas profundidades de 0,2 e $1,5 \mathrm{~m}$.

Harms e Chanasyk (2000) constataram, em solos de reconstrução, que o aumento da densidade diminuía a infiltração de água e aumentava o escoamento superficial. A elevação da densidade na profundidade de 1,5 m, oriunda do contato com o lixiviado, pode contribuir para reduzir a drenagem em profundidade, acumular água

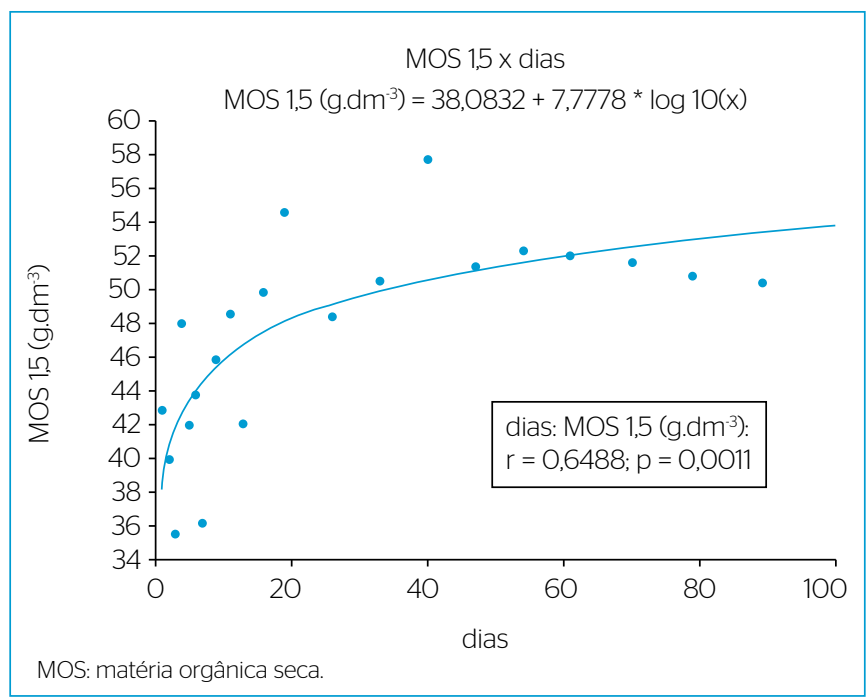

Figura 7 - Relação entre a matéria orgânica seca a 1,5 m e o tempo de contato no ensaio de difusão.

Tabela 1 - Densidade, macroporosidade e microporosidade do solo.

\begin{tabular}{l|c|c|c}
\multirow{2}{*}{$\begin{array}{l}\text { Latossolo } \\
\text { Vermelho }\end{array}$} & $\begin{array}{c}\text { Densidade } \\
\text { saturada }\left(\mathrm{g} \cdot \mathrm{mL}^{-1}\right)\end{array}$ & $\begin{array}{c}\text { Macroporosida- } \\
\text { de }\left(\mathrm{m}^{3} \cdot \mathrm{m}^{3}\right)\end{array}$ & $\begin{array}{c}\text { Microporosida- } \\
\text { de }\left(\mathrm{m}^{3} \cdot \mathrm{m}^{-3}\right)\end{array}$ \\
\hline $\begin{array}{l}\text { Profundidade de } \\
\text { 0,2 } \mathrm{m} \text { - água }\end{array}$ & 0,916 & 0,315 & 0,327 \\
\hline $\begin{array}{l}\text { Profundidade de } \\
\text { O,2 } \mathrm{m} \text { - lixiviado }\end{array}$ & 0,862 & 0,320 & 0,342 \\
\hline $\begin{array}{l}\text { Profundidade de } \\
1,5 \mathrm{~m} \text { - água }\end{array}$ & 0,909 & 0,335 & 0,298 \\
\hline $\begin{array}{l}\text { Profundidade de } \\
1,5 \mathrm{~m} \text { - lixiviado }\end{array}$ & 0,960 & 0,302 & 0,361 \\
\hline
\end{tabular}


em superfície e aumentar o escoamento superficial. Constata-se que, apesar do acréscimo de MOS a 1,5 m, mesmo sendo significativa, houve redução de macroporos. Tal restrição física contribui para a redução da aeração e o crescimento das plantas (INDORANTE; JANSEN; BOAST, 1981).

Logan et al. (1996) verificaram incremento na retenção de água em solo de textura silte-argilosa com elevadas doses de lodo de esgoto, o que pode ser justificado por aumento no teor de matéria orgânica ou redução da densidade do solo, caso do atual experimento com a amostra a $0,2 \mathrm{~m}$ de profundidade, pois esse solo sofreu redução de densidade.

As alterações na densidade do solo a $0,2 \mathrm{~m}$, quando em contato com o lixiviado, podem ocorrer, possivelmente, segundo Ferreira, Fernandes e Curi (1999), por causa da mineralogia oxídica, que confere ao solo uma melhor estrutura natural, e da caulinítica, em que a matéria orgânica adicionada pelo lixiviado promove maiores efeitos no aumento da agregação e volume do solo. Os resultados obtidos mostram que os efeitos da aplicação do lixiviado na redução da densidade do solo a 0,2 $\mathrm{m}$ dependem do tipo de solo e da quantidade de elementos presentes no líquido aplicado. Nesse contexto, Aggelides e Londra (2000) concluíram que a aplicação de 75,0 Mg.ha-1 de uma mistura de $62 \%$ de lixo doméstico, $21 \%$ de lodo de esgoto e $17 \%$ de serragem, até $0,15 \mathrm{~m}$ de profundidade, promoveu redução na densidade do solo de 1,37 para 1,20 e de 1,12 para 1,05 em solo de textura siltosa e argilosa, respectivamente, assim como o ensaio com a amostra a $0,2 \mathrm{~m}$, que também sofreu redução.

A macroporosidade das amostras de solo a 0,2 e 1,5 $\mathrm{m}$ é superior a $0,10 \mathrm{~m}^{3} \cdot \mathrm{m}^{-3}$, valor considerado o limite inferior para o bom crescimento e desenvolvimento da maioria das culturas de sequeiro (HILLEL, 1998), não comprometendo a fluxo hídrico no solo. Solos com poucos macroporos apresentam restrições ao crescimento vegetal e à infiltração de água.

Considerando o contato com o lixiviado, a macroporosidade do solo a $1,5 \mathrm{~m}$ de profundidade teve redução em torno de $11 \%$. Solos adensados também podem formar agregados grandes, os quais normalmente apresentam baixo volume de macroporos em relação à porosidade total, comprometendo, principalmente, o processo de infiltração da água no solo (BAVER; GADNER; GADNER, 1972). Em solos intensamente cultivados pelos preparos convencionais, o surgimento de camadas compactadas, com redução do volume de macroporos e aumento de microporos, caso da amostra a 1,5 $\mathrm{m}$ de profundidade, determina a diminuição do volume de poros ocupado pelo ar e o aumento na retenção de água (DALLA ROSA, 1981; BERTOL; SANTOS, 1995). Em decorrência disso, observa-se diminuição da taxa de infiltração de água no solo, com consequente aumento das taxas de escoamento superficial e de erosão hídrica (SCHICK et al., 2000). A redução na taxa de infiltração de água no solo é a propriedade que melhor reflete o grau de degradação do sistema poroso do solo (DALLA ROSA, 1981).

O aumento da microporosidade do solo a 1,5 m - em torno de $21,14 \%$ - e de sua densidade e a redução de macroporos podem indicar degradação do solo em termos agrícolas, quando em contato com o lixiviado. A aplicação desse líquido nesse solo pode ser comparada a manejos de solo que promovem aumento da densidade, com redução da percentagem de macroporos, reduzindo a taxa de infiltração de água no solo (DALLA ROSA, 1981; BERTOL, 1989).

A macroporosidade do solo a $0,2 \mathrm{~m}$ praticamente não sofreu alterações, não sendo passível de análise e comparação com o a 1,5 m. Em relação à microporosidade do solo a $0,2 \mathrm{~m}$, houve aumento em torno de $4,25 \%$, inferior ao do solo a $1,5 \mathrm{~m}$, provavelmente em função da menor incorporação de matéria orgânica por esse solo, conforme citado anteriormente.

\section{CONCLUSÕES}

Os resultados apresentados mostram que há efeito do lixiviado sobre a densidade, a macro e a microporosidade e a matéria orgânica do solo: com a densidade saturada, macro e microporosidades do solo sofrem alterações em contato com o lixiviado de resíduos sólidos urbanos e há transferência da matéria orgânica do lixiviado para o solo.

Quanto ao uso do lixiviado para fins agrícolas, constatou-se que, em relação à matéria orgânica, o uso é benéfico ao solo visto o incremento de nutrientes decorrentes da interação solo-lixiviado. Já em relação à taxa de infiltração do solo, analisada por sua porosidade, a quantidade aplicada de lixiviado demandaria cuidados, pois pode ser prejudicial ao solo.

\section{REFERÊNCIAS}

AGGELIDES, S.M.; LONDRA, P.A. (2000) Effects of compost produced from town wastes and sewage sludge on the physical properties of a loamy and clay soil. Bioresource Technology, v.71, n. 3, p. 253-259. http://dx.doi.org/10.1016/S0960-8524(99)00074-7
AMERICAN PUBLIC HEALTH ASSOCIATION (APHA); AMERICAN WATER WORKS ASSOCIATION (AWWA); WATER ENVIRONMENT FEDERATION (WEF). (2005) Standard Methods for the examination of water \& wastewater. Washington, D.C.: APHA. 
BARONE, F.S. (1989) Determination of Diffusion and Adsorption coefficients for some contaminants in clayey soil and rock: laboratory determination and field evaluation. Tese (Doutorado) University of Western, Ontário.

BARROS, F.M.; MARTINEZ, M.A.; NEVES, J.C.L.; MATOS, A.T. de; SILVA, D.D. da. (2005) Características químicas do solo influenciadas pela adição de água resíduária da suinocultura. Revista Brasileira de Engenharia Agrícola e Ambiental, v. 9, supl., p. 47-51.

BAVER, L.D.; GADNER, W.H.; GADNER, W.R. (1972) Soil structure: evaluation and agricultural significance. In: BAVER, L.D.; GARDNER, W.R. Soli physics. 4. ed. Nova York: John Wiley. p. 178-223.

BERTOL, I. (1989) Degradação física do solo sob a cultura do alho. Revista Agropecuária Catarinense, v. 2, p. 47-50.

BERTOL, I.; SANTOS, J.C.P. (1995) Uso do solo e propriedades físicohídricas no Planalto Catarinense. Pesquisa Agropecuária Brasileira Brasilia, v. 30, n. 2, p. 263-267.

BERTON, R.S.; CAMARGO, O.A.; VALADARES, J.M.A.S. (1989) Absorção de nutrientes pelo milho em resposta à adição de lodo de esgoto a cinco solos paulistas. Revista Brasileira de Ciência do Solo, v. 13, p. 187-192.

BERTON, R.S.; VALADARES, J.M.A.S.; CAMARGO, O.A.; BATAGLIA, O.C. (1997) Peletização do lodo de esgoto e adição de CaCO3 na produção de matéria seca e absorção de Zn, Cu e Ni pelo milho em três latossolos. Revista Brasileira de Ciência do Solo, Campinas, v. 21, n. 4, p. 685-691. http://dx.doi.org/10.1590/S010006831997000400020

DALLA ROSA, A. (1981) Práticas mecânicas e culturais na recuperaçao de caracteristicas fisicas de solos degradados pelo cultivo no solo Santo Angelo (Latossolo Roxo Distrofico). 138f. Dissertação (Mestrado) - Faculdade de Agronomia, Universidade Federal do Rio Grande do Sul, Porto Alegre.

DA ROS, C.O.; AITA, C.; CERETTA, C.A.; FRIES, M.R. (1993) Lodo de esgoto: efeito imediato no milheto e residual na associação aveiaervilhaca. Revista Brasileira de Ciência do Solo, v. 17, p. 257-261.

DEBOSZ, K.; PETERSEN, S.O.; KURE, L.K.; AMBUS, P. (2002) Evaluating effects of sewage sludge and household compost on soil physical, chemical and microbiological properties. Applied Soil Ecology, v. 19, n. 3, p. 237-248. http://dx.doi.org/10.1016/ S0929-1393(01)00191-3

EMPRESA BRASILEIRA DE PESQUISA AGROPECUÁRIA (EMBRAPA). (1997) Centro Nacional de Pesquisa de Solos. Manual de métodos de análise de solo. 2. ed. Rio de Janeiro: Embrapa. 212 p.

FERREIRA, M.M.; FERNANDES, B.; CURI, N. (1999) Influência da mineralogia da fração argila nas propriedades físicas de latossolos da Região Sudeste do Brasil. Revista Brasileira de Ciência do Solo, v. 23, n. 3, p. 515-524. http://dx.doi.org/10.1590/S010006831999000300004
GABAS, S.G. (2005) Avaliação da adsorção de cádmio e chumbo em solo laterítico compactado por meio de extração seqüencial. Tese (Doutorado) - Escola Politécnica, Universidade de São Paulo, São Paulo.

HARMS, T.E.; CHANASYK, D.S. (2000) Plot and small-watershed scale runoff from two reclaimed surface-mined watersheds in Alberta. Hydrological Processes, v. 14, n. 7. p. 1327-1339. https:/l doi.org/10.1002/(SICI)1099-1085(200005)14:7\%3C1327::AIDHYP63\%3E3.0.CO;2-7

HILLEL, D. (1998) Flow of water in unsaturated soil. In: Environmental soil physics. Nova York: Academic Press. p. 203-241.

INDORANTE, S.J.; JANSEN, I.J.; BOAST, C.W. (1981) Surface mining and reclamation: Initial changes in soil character. Journal of Soil and Water Conservation, v. 36, n. 6, p. 347-351.

KUMAR, S.; MALLIK, R.S.; DAHIYA, I.S. (1985) Influence of different wastes upon water retention, transmission and contact characteristics of sandy soil. Australian Journal of Soil Research. v. 23, p. 131-136.

LEITE, A.L. (2001) Migração de íns inorgânicos em alguns solos tropicais com ênfase nos processos de sorção e difusão molecular. Tese (Doutorado) - Escola de Engenharia de São Carlos, São Carlos.

LOGAN, T.J.; HARRISON, B.J.; MCAVOY, D.C; GREFF, J.A. (1996) Effects of olestra in sewage sludge on soil physical properties. Journal of Environmental Quality, v. 25, n. 1, p. 153-161. http://doi. org/10.2134/jeq1996.00472425002500010020x

MATHAN, K.K. (1994) Studies on the influence of long-term municipal sewage-effluent irrigation on soil physical properties. Bioresource Technology, v. 48, n. 3, p. 275-276. https://doi. org/10.1016/0960-8524(94)90159-7

MATOS, A.T; SEDIYAMA, M.A.N.; FREITAS, S.P.; VIDIGAL, S.M.; GARCIA, N.C.P. (1997) Características químicas e microbiológicas do solo influenciadas pela aplicação de dejeto líquido de suínos. Revista Ceres, v. 44, n. 254, p. 399-410.

MCSWEENEY, K: JANSEN, I.J. (1984) Soil structure and associated rooting behavior in minesoils. Soil Science Society of America Journal, v. 48, n. 3, p. 607-612. https://doi.org/10.2136/ sssaj1984.03615995004800030028x

METZGER, L:; YARON, B. (1987) Influence of sludge organic matter on soil physical properties. Advances in Soil Science, v. 7, p. 141-163. https://doi.org/10.1007/978-1-4612-4790-6_4

ORTEGA, E.; NOGALES, R.; DELGADO, M. (1981) Modificación en La porosidad de un suelo por la adición de un compost de basura urbana. Anales de Edafología y Agrobiología, v. 15, p. 1735-1747.

PAGLIAI, M.; GUIDI, G.; LA MARCA, M.; GIACHETTI, M.; LUCAMANTE, G. (1981) Effects of sewage sludge and composts on soil porosity and aggregation. Journal of Environmental Quality, v. 10, n. 4, p. 556561. https://doi.org/10.2134/jeq1981.00472425001000040028x 
RITTER, E.; CAMPOS, J.C. (2006) Avaliação da sorção e difusão de íons inorgânicos do chorume e da argila orgânica do Aterro Metropolitano de Gramacho (RJ). Solos e Rochas, v. 29, n. 1, p. 77-88.

SCHICK, J.; BERTOL, I.; BALBINOT JUNIOR, A.A.; BATISTELA, O. (2000) Erosão hídrica em cambissolo húmico alumínico submetido a diferentes sistemas de preparo e cultivo do solo: II. Perdas de nutrientes e carbono orgânico. Revista Brasileira Ciência do Solo, v. 24, n. 2, p. 437-447. http://dx.doi.org/10.1590/S010006832000000200020
SILVA, F.C.; BOARETTO, A.E.; BERTON, R.S.; ZOTELLI, B.; PEXE, C.A.; BERNARDES, E.M. (2001) Efeito do lodo de esgoto na fertilidade de um Argissolo Vermelho-Amarelo cultivado com cana-de-açúcar. Pesquisa Agropecuária Brasileira, v. 36, n. 5, p. 831-840. http://dx.doi. org/10.1590/S0100-204X2001000500014

SIMONETE, M.A.; KIEHL, J. de C:; ANDRADE, C.A.; TEIXEIRA, C.F.A. (2003) Efeito do lodo de esgoto em um Argissolo e no crescimento e nutrição de milho. Pesquisa Agropecuária Brasileira, v. 38, n. 10, p. 1187-1195. http://dx.doi.org/10.1590/S0100-204X2003001000008 